\title{
Importance of Furugelm Island in the Sea of Japan for wetland birds: the first record of a breeding colony of the Chinese egret Egretta eulophotes
}

\author{
Natalia M. Litvinenko and Yuriy V. Shibaev
}

\begin{abstract}
A new breeding site of the globally threatened Chinese egret Egretta eulophotes was recorded on Furugelm Island in the summer of 1998. The discovery of this colony moves the breeding limit of the species more than $600 \mathrm{~km}$ further to the north-east in the Sea of Japan. Thirty to forty pairs of Chinese egrets were discovered on the island, which is also home to thousands of colonial seabirds as well. The egret's colony is within the FarEastern Marine Reserve but some of its main foraging sites lie outside the protected area and are disturbed by both tourists and hunters. More worryingly, however,
\end{abstract}

the main threat to the Chinese egret's survival is a new economic development project: the Tumen River Area Development Program. We make an urgent plea for the protection of the Chinese egrets' foraging areas within the Far-Eastern Marine Reserve and recommend that a transfrontier reserve be created to enhance the protection of this important waterbird site.

Keywords Chinese egret, endangered species, Egretta eulophotes, new breeding site, population status, Sea of Japan, threats.
A new breeding site of the Chinese egret Egretta eulophotes was recorded on Furugelm Island near the mouth of the Tumen (Tumangan) River (Fig. 1) in the summer of 1998 . The discovery of this colony moves the breeding limit of the species more than $600 \mathrm{~km}$ further to the north-east in the Sea of Japan. To date, the Chinese egret was known to nest only on islands in the Yellow Sea (Lansdown, 1990). This finding has proved the prediction by Lansdown, regarding the probability of this species breeding in Ussuriland, to be correct (pers. comm., March 1988).

The Chinese egret is a globally threatened species. The total breeding population has been estimated at 960 pairs (Lansdown, 1990). We can state with confidence that the Chinese egret did not nest on Furugelm Island before 1992, because we often visited this island in the $1970 \mathrm{~s}$ and 1980s. Birds were recorded for the first time in the vicinity of Furugelm Island in summer 1992; since then, Chinese egrets have been observed annually. They feed on coastal lagoons and, on occasions, we have recorded birds flying near the coast of the island.

Natalia M. Litvinenko (corresponding author) Laboratory of Ornithology, Institute of Biology and Soil Sciences, Far Eastern Branch of Russian Academy of Sciences, Vladivostok, 690022, Russia. Tel: + 4232 311180; fax: + 4232 314605; e-mail: litvinenko@mail.primorye.ru

Yuriy V. Shibaev Laboratory of Zoology, Institute of Biology and Soil Sciences, Far Eastern Branch of Russian Academy of Sciences, Vladivostok, 690022, Russia. Tel: + 4232 311180; fax:

+ 4232 314605; e-mail: litvinenko@mail.primorye.ru

Revised manuscript accepted for publication 18 April 2000
Until recently, the Chinese egret was regarded as a vagrant bird in Russia. Usually single birds or, rarely, small flocks were seen, and only on Primorye Territory (Labzyuk, 1981; Nazarov, 1989). The first observation was on 28 June 1915 at Olympiad Cape in Northern Primorye (Shulpin, 1936).

Furugelm Island is the most southerly island in the Russian Ear East. It is about $3.5 \mathrm{~km}$ long, has a rocky and abrupt coastline and is covered with a broadleaf forest and patches of grass thicket. Thousands of colonial birds nest on the coastal cliffs and grassy slopes, including cormorants (Phalacrocorax filamentosus, Ph. carbo, Ph. pelagicus), gulls (Larus crassirostris, L. schistisagus), auks (Cepphus carbo, Synthliboramphus antiquis, Cerorhinca monocerata) and grey heron (Ardea cinerea).

There are about $35-40$ pairs of Chinese egrets on Furugelm Island. The colony is situated on a rocky crest near the sea (Plates 1 and 2). The Chinese egret breeds in association with the grey heron, Temminck's cormorant, black-tailed and slaty-backed gulls and the spectacled guillemot. Most nests are built in bushes of elder Sambucus latipinna, the remainder are constructed directly on the ground, mainly in wormwood Artemisia gmelini thicket. Findings include the following: clutch size $(n=6)$ : three eggs ( 100 per cent); brood size ( $n=$ 22): one ( 4.5 per cent), two ( 31.8 per cent) and three (63.6 per cent) chicks. We have no exact data on the reproductive success of the population, but we can say confidently that it was successful in 1998: all 35 chicks, of different ages from 14 broods that were found on 10 July, have fledged and left the island.

The Chinese egrets' feeding sites are brackish lagoons and shallow sea bays on the coast between the mouth 


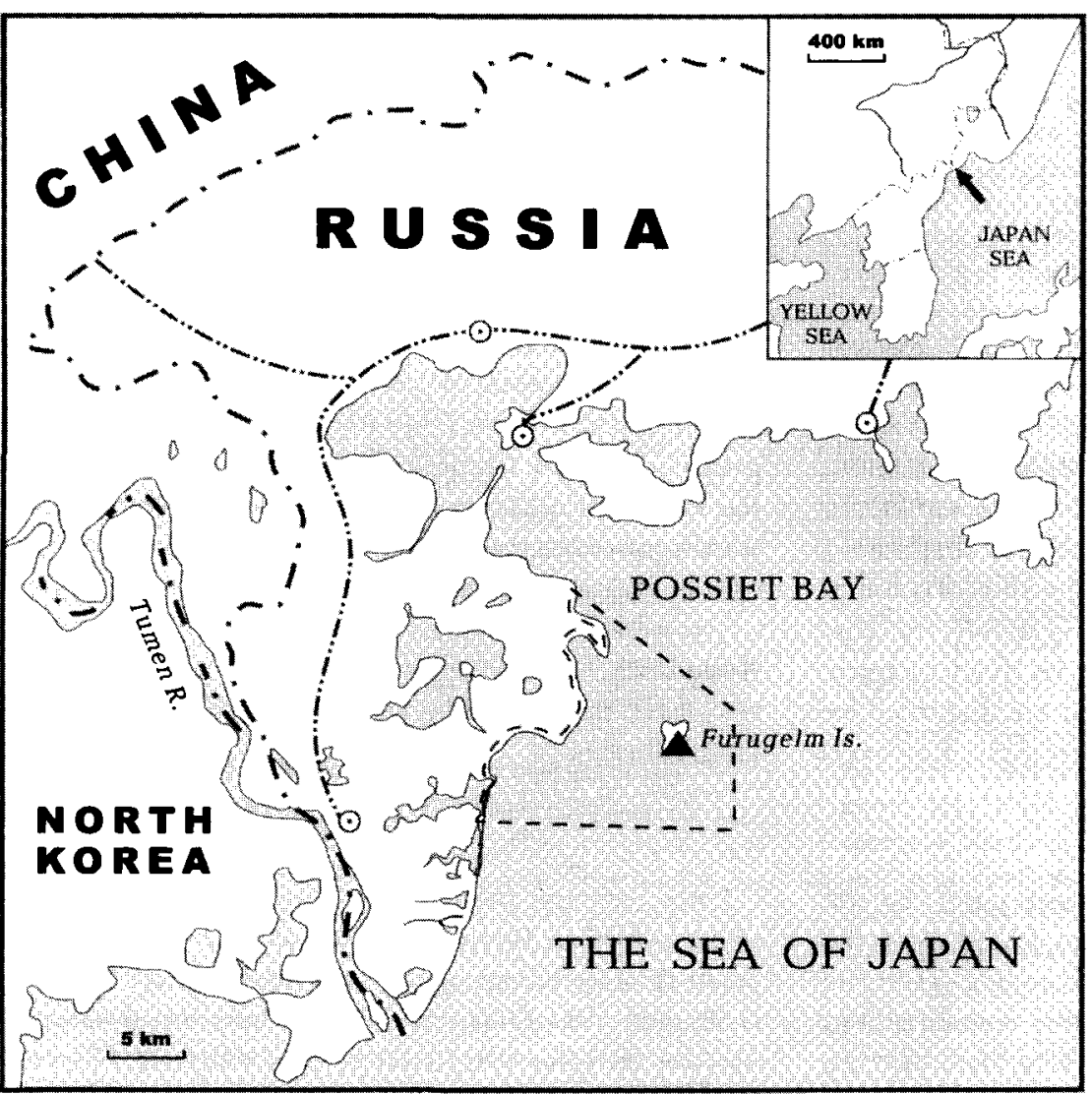

Fig. 1 Furugelm Island and its location within the Sea of Japan. Key: triangle = location of Chinese egret breeding colony; broken line = boundary of the Far-Eastern Marine Reserve. of the Tumen River and Possiet Bay. The nearest feeding lagoons are approximately $15 \mathrm{~km}$ from the colony (Plate 3).

The formation of the breeding colony of Chinese egret on Furugelm Island increases the chance of survival of this endangered species. The island is included in the territory of the Far-Eastern Marine Reserve and the colony is under reliable protection, although the main foraging sites of the egret on the seacoast are outside protected territory. Tourists and hunters visit this area and disturb the birds. The main threat, however, is a large-scale economic development project called the Tumen River Area Development Program (TRADP), introduced in this area within the framework of the United Nations Development Programme (UNDP). This project will damage not only the Chinese egret but many other birds as well.

It is known (Shibaev \& Litvinenko, 1994; Litvinenko \& Shibaev, 1996) that the wetland in the TRADP area, situated in the low reaches of the Tumen River, supports high levels of bird diversity. More than 350 bird species have been recorded in this area, of which 40 are included in the IUCN (1996) Red List of Threatened Animals. For example, red-crowned cranes Grus japonensis and white-naped cranes $G$. vipio, live in the wetland each spring and autumn (about 300 birds of each species) (Shibaev \& Surmach, 1994); which accounts for more than 10 per cent of the world's population of red-crowned cranes. Baer's pochard Aythya baeri also breeds in this area. Shallow reservoirs (brackish and freshwater) with high productivity levels support numerous migratory waterbirds. It is one of the most important waterbird sites in the East Asian-Australasian flyway. Annually, the wetland supports more

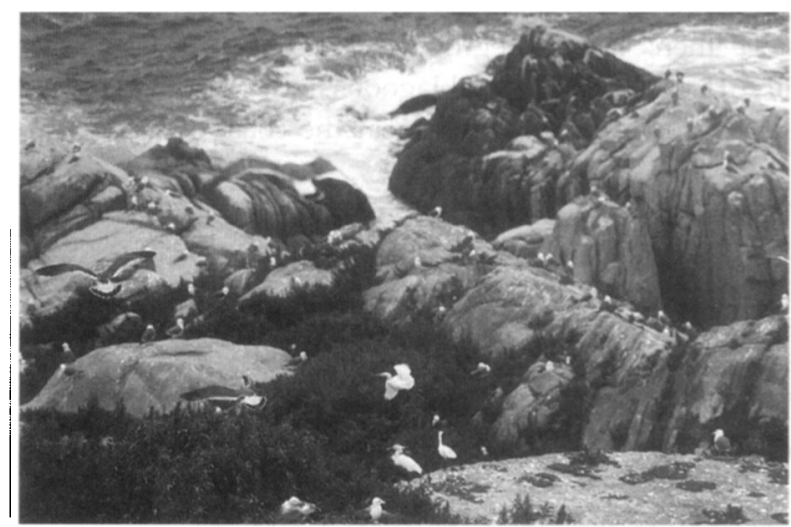

Plate 1 Breeding colony of the Chinese egret on Furugelm Island. 


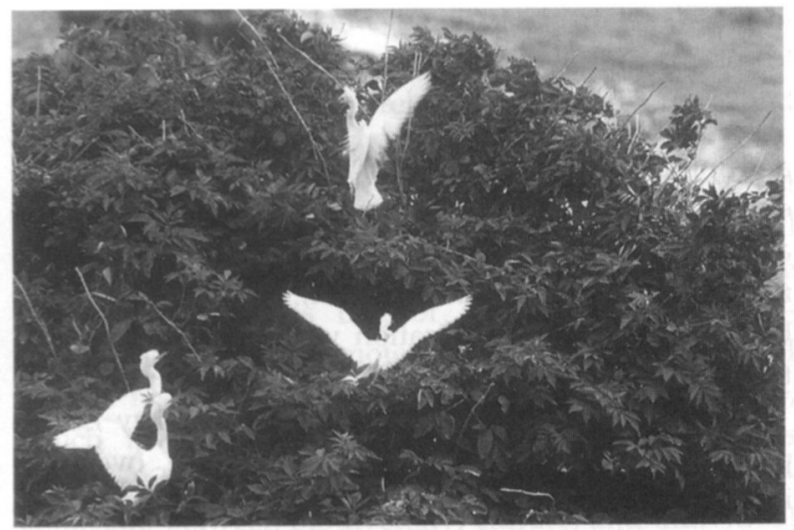

Plate 2 Family (adult and fledglings) of Chinese egrets in the colony.

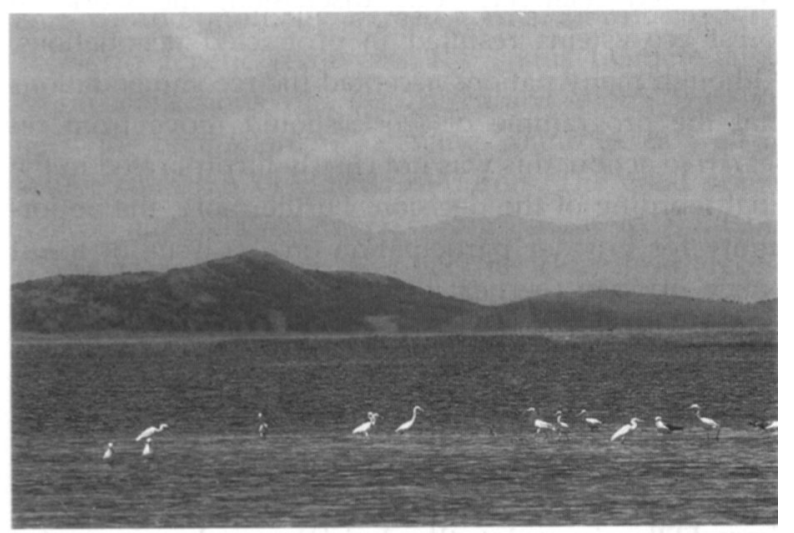

Plate 3 Chinese egrets and black-tailed gulls on the brackish lagoon.

than 20,000 waterfowl. It has been demonstrated that this area meets a number of Ramsar criteria (Litvinenko \& Shibaev, 1996).

There is an urgent need to include the foraging area of the Chinese egrets that breed on Furugelm Island within the Far-Eastern Marine Reserve. Follow-up steps should begin with the inclusion of the entire wetland on the Ramsar List and the creation of a transfrontier 'Tumangan' Reserve that incorporates the international boundaries of Russia, China and North Korea. The discovery of a breeding colony of Chinese egrets is another argument in support of the improvement of the resource protection system in this area.

\section{Acknowledgements}

We are grateful to the staff and the administration of the Far-Eastern Marine Reserve for facilities to study the birds within the reserve and for providing us with sea transport. We thank A. Ratnikov and E. Chubar for field assistance in the search for Chinese egret nesting sites.

\section{References}

IUCN (1996) Red List of Threntened Animals. IUCN, Gland, Switzerland.

Labzyuk, V.I. (1981) Records of rare birds in the Olga Bay (South Prymorie). In Rare Birds of the Far East, Far East Branch of Russian Academy of Sciences (ed. N.M. Litvinenko), pp. 122-123. Vladivostok Publishing House, Vladivostok.

Lansdown, R. (1990) Little known oriental bird: Chinese egret. Bulletin of the Oriental Bird Club, 11, 27-30.

Litvinenko, N.M. \& Shibaev, Yu.V. (1996) Importance of the lower reaches of the Tumangan river for bird diversity (Materials for organization of national park and additional Ramsar site). In Birds of the Wetlands of the Southern Russian Far-East and their Protection (ed. N. M. Litvinenko), pp. 49-75. Dalnauka Press, Vladivostok.

Nazarov, Yu.N. (1989) The Chinese egret Egretta eulophotes. In Rare vertebrates of the Far East and their Protection (eds V.A. Kostenko, P.A. Ler, V.A. Nechaev and Yu.V. Shibaev), pp. 50-51. Nauka Publishing House, Leningrad. Shibaev, Yu.V. \& Litvinenko, N.M. (1994) Border nature reserves on the wetlands of the South Far East. In Bridges of Science between North America and the Russian Far East (eds R.H. Meehan, V. Sergienko and G. Weller), pp. 70-74. Proceedings of the 45th Arctic Science Conference, Anchorage, Vladivostok.

Shibaev, Y.V. \& Surmach, S.G. (1994) Autumn migration of red-crowned and white-naped cranes, Grus japonensis and G. vipio, in Primorye Region, Far East Russia. In The Future of Cranes and Wetlands (eds $\mathrm{H}$. Higuchi and $\mathrm{J}$. Minton), pp. 114-120. Wild Bird Society of Japan, Tokyo. Shulpin, L.M. (1936) Hunting and Predatory Birds of the Primorye. Vladivostok Publishing House, Vladivostok.

\section{Biographical sketches}

Natalia M. Litvinenko is a senior researcher at the Laboratory for Ornithology, Far Eastern Branch of Russian Academy of Sciences in Vladivostok. Her research interests include the modern status, distribution, biology and conservation of wetland and seabirds of the southern part of the Russian Far East. Dr Litvinenko is a member of the Seabirds Specialist Group of the IUCN Species Survival Commission. She has published more than 90 scientific publications in Russian and English.

Yuriy V. Shibaev is a senior researcher at the Laboratory of Zoology, Far Eastern Branch of Russian Academy of Sciences in Vladivostok. His research interests include the modern status, distribution, migration and conservation of wetland and certain endangered birds and the organization of nature-protected territories on the wetlands of the southern part of the Russian Far East. Dr Shibaev is a member of the Cranes Specialist Group of the IUCN Species Survival Commission. He has published more than 100 scientific publications. 